\title{
Cecal volvulus: classic imaging appearance of an uncommon pediatric entity
}

\author{
Grace Phillips • Marguerite T. Parisi
}

Received: 21 November 2009/Revised: 14 January 2010/Accepted: 5 February 2010 / Published online: 25 March 2010

(C) Springer-Verlag 2010

\begin{abstract}
A 13-year-old boy presented with a 1-day history of coffeeground emesis. Pertinent medical history included trisomy 17, developmental delay, and chronic constipation. Supine abdominal radiograph (Fig. 1) demonstrated gaseous distention of malpositioned colon located in the left upper quadrant. Upper GI (not shown) revealed malrotation without midgut volvulus. Enema (Fig. 2) showed beaked cut-off of contrast column (arrow), typical of cecal volvulus, and residual contrast agent from UGI $(C)$. Both malrotation and cecal volvulus were surgically confirmed.
\end{abstract}

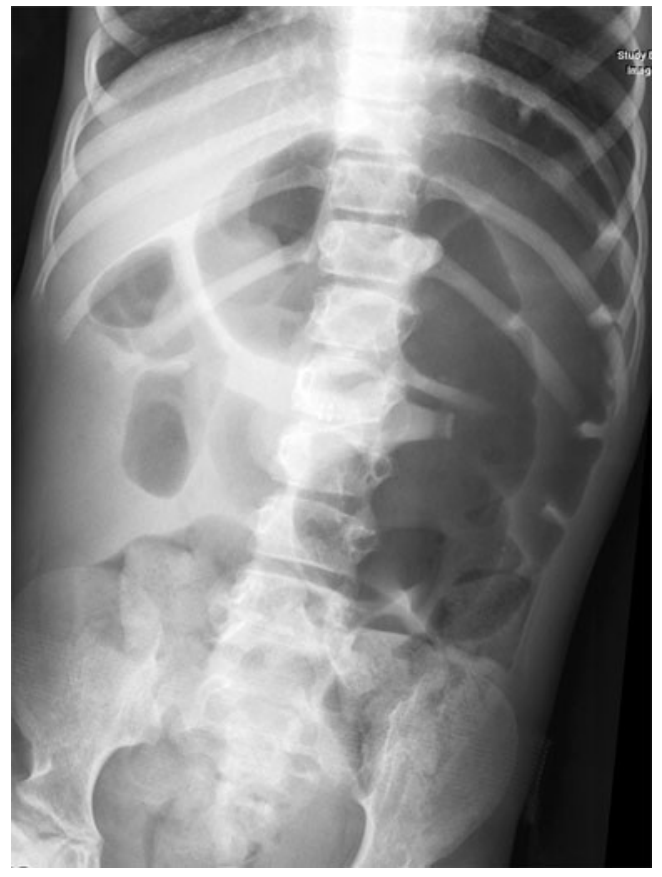

Fig. 1 Supine abdominal radiograph

G. Phillips $(\bowtie) \cdot$ M. T. Parisi

Department of Radiology, Seattle Children's Hospital,

4800 Sandpoint Way NE,

Seattle, WA 98105, USA

e-mail: grace.phillips@seattlechildrens.org

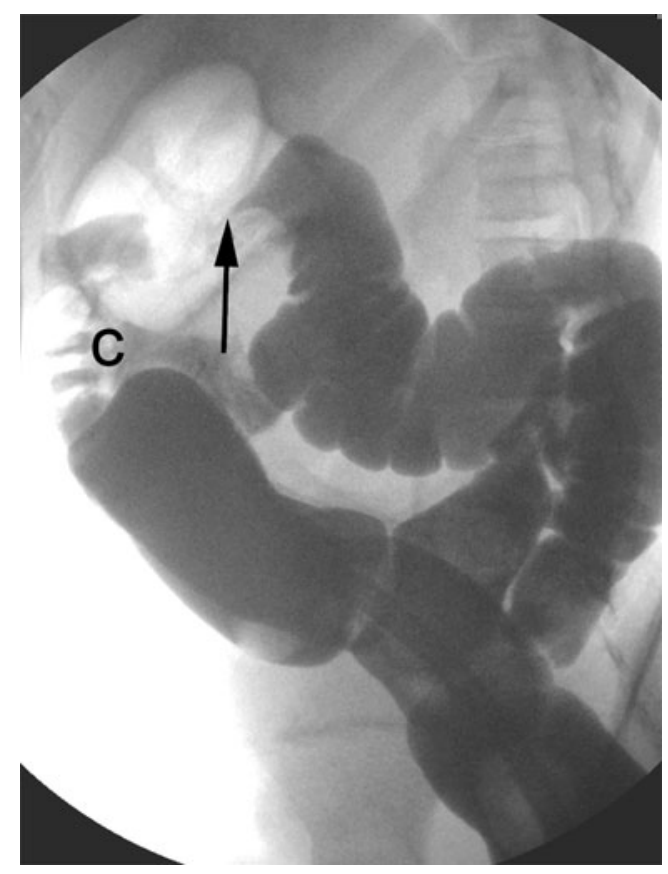

Fig. 2 Contrast enema

Cecal volvulus is extremely rare in children. Common associations include developmental delay, chronic constipation and malrotation. A mobile cecum is invariably present. Complications of cecal gangrene and perforation occur in 19$52 \%$ [1]; overall mortality is $10 \%$ [2]. The mainstay of diagnostic imaging remains the contrast enema. A high index of suspicion in at-risk children can reduce the high morbidity and mortality associated with this condition.

\section{References}

1. Takada K, Hamada Y, Sato M et al (2007) Cecal volvulus in children with mental disability. Pediatr Surg Int 23:1011-1014

2. Kirks DR, Swischuk LE, Merten DF et al (1981) Cecal volvulus in children. AJR 136:419-422 